\title{
Psychiatric Symptoms and Hostility in a Group of Schizophrenic Patients
}

\author{
Balta GT, Angelopoulos NV
}

\begin{abstract}
Purpose: The aim of this study was to investigate the relationships between hostility features and psychiatric symptomatology in a population of schizophrenic patients.

Methods: The Hostility and Direction of Hostility Questionnaire (HDHQ) and the Delusions Symptoms States Inventory (DSSI) were administered to 172 patients given the diagnosis of schizophrenia.

Results: Significant relationships were found between the HDHQ hostility subscales and certain psychiatric symptoms. Acting Out Hostility mainly with Phobic symptoms and state of Elation. Criticism of Others mainly with Compulsive symptoms. Paranoid Hostility mainly with Delusions of Persecution, Delusions of Disintegration and Dissociative Symptoms. SelfCriticism mainly with Delusions of Contrition and Phobic symptoms. Guilt with Delusions of Contrition, Depressive symptoms and Phobic symptoms.

Index Terms - Hostility, schizophrenia.
\end{abstract}

\section{INTRODUCTION}

and psychiatric illness has not only a theoretical interest but also direct implications in the everyday psychiatric practice. This relationship has had been a matter of

extensive study and discussion.

It seems that there is not universal agreement regarding the relationship of hostility to the majority of psychiatric disturbances, except in the cases of mania and paranoid states for both of which it is generally accepted that outwardly directed hostility is a consistent accompaniment. There is also a general tendency to associate introverted hostility with neurotic symptoms and depression.

It has been found that psychiatric patients experience or, to a lesser degree, express high levels of hostility [1-3]. It hasbeen also found that normal people without psychiatric symptoms present significantly lower levels of hostility than either "normal people with psychiatric people who do not suffer a breakdown" or neurotic patients [4].

The problem of the relationship between hostility and psychopathology could be more fruitfully examined not in

Georgia T. Balta, M.D, Ph. D, University of Thessaly, Medical School, Department of Psychiatry, Biopolis, Larissa, Greece

Nikiforos V. Angelopoulos, Professor of Psychiatry, University of Thessaly, Medical School, Department of Psychiatry, Biopolis, Larissa, Greece general terms but by considering the relationships of specific hostility features with certain psychiatric symptoms in well-defined diagnostic categories. such as schizophrenia.

\section{SUBJECTS AND METHOD}

The Hostility and Direction of Hostility Questionnaire (HDHQ) and the Delusions Symptoms States Inventory (DSSI) were administered to 172 hospitalized schizophrenic patients in three different psychiatric establishments: Tripolis psychiatric institution, the psychiatric department of state prisons and a private psychiatric clinic.

The HDHQ [5] is an attitudinal measure for a wide range of possible manifestations of hostility, having little implication of aggressive behaviour physically expressed. Two dimensions underlie hostility as it is measured by the HDHQ: a readiness to respond with aggressive behaviour and a tendency to evaluate persons, including the self, in negative terms. It consists of five subscales in 52 items. Three subscales, acting-out hostility $(\mathrm{AH})$, criticism of others $(\mathrm{CO})$ and paranoid hostility $(\mathrm{PH})$ are measures of total extrapunitiveness (TE). Two subscales, guilt (G) and self-criticism (SC) are measures of total intropunitiveness (TI). Total hostility (TH) is the sum of the five subscales. The accepted norms for total hostility in normal populations are between 12-14 [5] but higher norms have been also suggested [6]. The HDHQ has been used in Greek normal populations [7] and psychiatric [8] or somatic [9, 10] patients. Normative data from Greek healthy groups suggest Total Hostility score around 15.0.

The DSSI $[11,12]$ is consisted of 84 items in twelve sets, allocated in four Classes: Class I, Dysthymic States: State of Anxiety (sA), State of Depression (sD), State of Elation (sE). Class II, Neurotic Symptoms: Conversion Symptoms (PS), Dissociative Symptoms (DS), Phobic Symptoms (FS), Compulsive Symptoms (CS), Ruminative Symptoms (RS). Class III, Integrated Delusions: Delusions of Persecution (dP), Delusions of Grandeur $(\mathrm{dG})$, Delusions of Contrition (dC). Class IV Delusions of Disintegration (DD). Each item is scored 0, 1, 2, and 3 according to the degree of distress, or in the case of delusions upon the certainty of the belief. A score of four or more on any set of items is the criterion for membership of that set and the class of which it is a constituent.

The statistical analysis was carried out using the Statistical Package for the Social Sciences [13].For the 
ordinal variables the nonparametric rank-order correlation coefficient Kendall's $\tau$-b [14] was used. The case for using this correlation coefficient with psychometric data has been argued by Priest [15].

\section{RESULTS}

One hundred and seventy-three patients, 156 males and 17 females participated in the study. Mean age in years 33.2 (sd 9.6). Duration of illness 9.01 years (sd 2.39).

High levels of hostility were reported (Total Hostility score: 24.5 ). (Table 1 ).

Table 1. HDHQ scores.Means and standard deviations. $(\mathrm{N}=172)$

\begin{tabular}{|l|l|l|}
\hline & means & sd \\
\hline Acting Out Hostility & 5.17 & 2.55 \\
\hline Criticism of Others & 7.06 & 2.39 \\
\hline Paranoid Hostility & 4.13 & 2.42 \\
\hline Self Criticism & 3.33 & 1.93 \\
\hline Guilt & 4.85 & 2.07 \\
\hline Intropunitiveness & 8.13 & 3.38 \\
\hline Extrapunitiveness & 16.37 & 5.91 \\
\hline Total Hostility & 24.51 & 7.94 \\
\hline
\end{tabular}

On the DSSI psychiatric symptoms the percentages of the patients reported scores higher than three were as follows in descending order: State of Elation, 55.9. State of Depression, 55.3. State of Anxiety, 52.4. Ruminative Symptoms, 47.7. Compulsive Symptoms, 44.7. Delusions of Persecution, 44.1. Phobic Symptoms, 41.8. Delusions of Grandeur, 41.2. Dissociative Symptoms, 40.0. Delusions of Contrition, 37.7. Delusions of Disintegration, 37.7. Conversion Symptoms, 33.5. (Table 2).

Table 2. Percentages of the patients reported high scores $(\geq 4)$ on DSSI

\begin{tabular}{|l|c|c|}
\hline & \multicolumn{2}{|c|}{ score $\geq 4$} \\
\hline & $a)$ & $N$ \\
\hline State of Anxiety & 89 & 52.4 \\
\hline State of Depression & 94 & 55.3 \\
\hline State of Elation & 95 & 55.9 \\
\hline Conversion Symptoms & 57 & 33.5 \\
\hline Dissociative Symptoms & 68 & 40 \\
\hline Phobic Symptoms & 71 & 41.8 \\
\hline Compulsive Symptoms & 93 & 44.7 \\
\hline Ruminative Symptoms & 76 & 47.7 \\
\hline Delusions of Grandeur & 70 & 41.2 \\
\hline Delusions of Persecution & 75 & 44.1 \\
\hline Delusions of Contrition & 64 & 37.7 \\
\hline Delusions of Disintegration & 64 & 37.7 \\
\hline
\end{tabular}

Means and standard deviations of DSSI are demonstrated in table 3 .
Table 3. DSSI. Means and standard deviations.

\begin{tabular}{|l|l|l|}
\hline & mean & sd \\
\hline State of Anxiety & 4.8 & 4.5 \\
\hline State of Depression & 5.1 & 4.5 \\
\hline State of Elation & 5.1 & 4.2 \\
\hline Conversion Symptoms & 3.2 & 4.1 \\
\hline Dissociative Symptoms & 3.8 & 4.4 \\
\hline Phobic Symptoms & 3.3 & 3.8 \\
\hline Compulsive Symptoms & 4.9 & 4.3 \\
\hline Ruminative Symptoms & 4.0 & 4.1 \\
\hline Delusions of Grandeur & 3.5 & 3.7 \\
\hline Delusions of Persecution & 4.5 & 4.8 \\
\hline Delusions of Contrition & 3.5 & 3.7 \\
\hline Delusions of Disintegration & 3.4 & 4.0 \\
\hline
\end{tabular}

As far as the relationships between the HDHQ (Table 4) hostility subscales and the DSSI psychiatric symptoms are concerned, the following were observed:

State of Anxiety (sA). Highly significant correlations with Paranoid Hostility and Total Hostility. No significant correlations with Criticism of Others and Guilt.

State of Depression (sD). Highly significant correlations with Paranoid Hostility and Total Hostility. No significant correlations with Criticism of Others.

State of Elation (sE). Highly significant correlations with Acting Out Hostility, Total Extrapunitiveness and Total Hostility. No significant correlations with Guilt.

Conversion Symptoms (PS). Highly significant correlations with Acting Out Hostility and Total Hostility. No significant correlations with Acting Out Hostility and Criticism of Others.

Dissociative Symptoms (DS). Highly significant correlations with Paranoid Hostility, Total Extrapunitiveness and Total Hostility.

Phobic Symptoms (FS). Highly significant correlations with Acting Out Hostility, Guilt, Total Intropunitiveness and Total Extrapunitiveness. No significant correlations with Criticism of Others.

Compulsive Symptoms (CS). Highly significant correlations with Paranoid Hostility, Guilt, Total Intropunitiveness and Total Extrapunitiveness.

Ruminative Symptoms (RS). Highly significant correlations with Paranoid Hostility, and Total Extrapunitiveness. No significant correlations with Criticism of Others and Guilt.

Delusions of Grandeur (dG). Highly significant correlations with Paranoid Hostility, and Total Extrapunitiveness. No significant correlations with Criticism of Others, Self-Criticism and Guilt.

Delusions of Persecution (dP). Highly significant correlations with Paranoid Hostility, and Total Extrapunitiveness. No significant correlations with Self Criticism, Guilt and Total Intropunitiveness.

Delusions of Contrition (dC). Highly significant correlations with Paranoid Hostility, Guilt, Total Intropunitiveness and Total Hostility. No significant correlations Acting Out Hostility.

Delusions of Disintegration (DD). Highly significant 
correlations with Paranoid Hostility, and Total Extrapunitiveness. No significant correlations with Self Criticism, Guilt and Total Intropunitiveness.

\section{DISCUSSION}

Schizophrenic patients have been considered $[2,5]$ to be the most generally punitive group. Concerning their direction of hostility Foulds [2] noted that there is a tendency for schizophrenics to score predominantly in the extrapunitive direction, whereas Jung [16] associated "dementia praecox" with introversion. It seems however that the direction of hostility depents on the kind of the delusional ideasthe schizophrenic patient has. Foulds and Bedford [17] found that schizophrenic patients with delusions of contrition scored, as one could expect, much higher on intropunutiveness than those with delusions of grandeur.

It would nevertheless be of importance, if it were possible, to examine the level and direction of hostility in the very small minority of schizophrenics without integrated delusions as far as its relation to their symptoms is concerned. More "pure" symptoms of a non-integrated psychotic can be regarded symptoms implying a breakdown of the boundary between self and others and a disturbance of the patient's awareness of himself as an agent; auditory hallucinations, delusions of thought incertion and of thought broadcasting; flattening and incongruity of affect and thought disorder could also be regarded as symptoms manifested by non-integrated psychotics. Priest [18] hypothesized that thought disorder in non-integrated psychotics would be associated with high levels of hostility; chronic schizophrenics tend to use their thought disorder to avoid communication. In this way, they are able to avoid indicating their distrust and hostility. These patients become intropunitive after the removal of this symptom during the treatment.

Hostility has been regarded as an attitude and being in an intermediate position (as far as stability, universality and the cause of distress are concerned) between personality traits (regarded as stable, universal and ego syntonic) and psychiatric symptoms regarded as transient, sporadically found in the general population and causing distress to the individual [2].

In the present study, it was observed that hostility has indeed a noteworthy affinity to psychiatric symptomatology and being very much influenced by the underlying psychopathology.

Paranoid hostility was found positively and significantly related to all studied psychiatric symptoms. The closest relationships detected were those with Delusions of Persecution, Dissociative symptoms and Delusions of Disintegration. This finding is probably related not only to the fact that the studied population is constituted solely by schizophrenics but also to the assumption that the delusional scale of Paranoid Hostility is much close to the psychiatric rather than to the personality dimension of the schizophrenic patients.

Certain HDHQ subscales have closer relationships to certain psychiatric symptoms such as Paranoid Hostility with delusions of Persecution and Guilt with delusions of Contrition. This probably suggest that these HDHQ subscales are closer to the psychopathology dimension.

Other subscales such as Criticism of others seem to be closer to the personality dimension.

It is also interesting to note that non-significant relationships between delusions of Grandeur and Self-criticism, delusions of Persecution and self-criticism, delusions of contrition and Acting-out hostility, state of Elation and Guilt, state of Depression and Criticism of others were observed which are very much expected.

\section{ACKNOWLEDGEMENTS}

We would like to thank Economou M., Pratikakis E., Zojes D. and Doga H. for their valuable contribution. 
Table 4. Kendall's $\tau$-b correlation coefficients (two-tailed) between DSSI/sAD and HDHQ subscales.

\begin{tabular}{|c|c|c|c|c|c|c|c|c|}
\hline & $\mathrm{AH}$ & $\mathrm{CO}$ & $\mathrm{PH}$ & $\mathrm{SC}$ & $\mathrm{G}$ & $\mathrm{TI}$ & $\mathrm{TE}$ & $\mathrm{TH}$ \\
\hline State & 233.000 & .123 .032 & $.320 \quad .000$ & .200 .000 & $\begin{array}{|ll|}183 & .002 \\
\end{array}$ & $\begin{array}{|ll|}.218 & .000 \\
\end{array}$ & \begin{tabular}{|ll}
269.000 \\
\end{tabular} & \begin{tabular}{|ll}
282.000 \\
\end{tabular} \\
\hline State & $\begin{array}{lll}.000 \\
\end{array}$ & .062 .237 & .318 .000 & .232 .000 & $.290 \quad .000$ & .289 .000 & 231.000 & $294 \quad .000$ \\
\hline Stat & $\begin{array}{|ll|}.000 \\
\end{array}$ & .205 .000 & .252 .000 & .249 .000 & $\begin{array}{|ll|}.165 & .004 \\
\end{array}$ & \begin{tabular}{|lll}
.240 & .000 \\
\end{tabular} & \begin{tabular}{|ll}
295 & .000 \\
\end{tabular} & \begin{tabular}{|ll}
313.000 \\
\end{tabular} \\
\hline Con & $\begin{array}{|ll|}.002 & .002 \\
\end{array}$ & .115 .050 & $.331 \quad .000$ & .237 .000 & $\begin{array}{|ll|}.245 & .000 \\
\end{array}$ & $.262 \quad .000$ & \begin{tabular}{|ll}
248.000 \\
\end{tabular} & \begin{tabular}{|ll}
296 & 000 \\
\end{tabular} \\
\hline Dis & $\begin{array}{|ll|}.255 & .000 \\
\end{array}$ & .212 .000 & $.370 \quad .000$ & .254 .000 & $\begin{array}{|ll|}.245 & .000 \\
\end{array}$ & \begin{tabular}{|lll}
.270 & .000 \\
\end{tabular} & \begin{tabular}{|ll}
$332 \quad .000$ \\
\end{tabular} & $306 \quad .000$ \\
\hline $\mathrm{Phc}$ & $\begin{array}{lll}.301 & .000 \\
\end{array}$ & .183 .002 & .289 .000 & .286 .000 & $.306 \quad .000$ & $.321 \quad .000$ & 313.000 & $372 \quad .000$ \\
\hline & $\begin{array}{|ll|}.273 & .000 \\
\end{array}$ & .216 .000 & $.331 \quad .000$ & .206 .000 & $\begin{array}{|ll|}.240 & .000 \\
\end{array}$ & $\begin{array}{|ll|}.245 & .000 \\
\end{array}$ & 342.000 & 343.000 \\
\hline & $\begin{array}{|ll|}.000 \\
\end{array}$ & .126 .028 & .304 .000 & .226 .000 & $\begin{array}{|ll|}.002 & .002 \\
\end{array}$ & $\begin{array}{|ll|}.228 & .000 \\
\end{array}$ & 276.000 & \begin{tabular}{|lll}
307 & .000 \\
\end{tabular} \\
\hline & $\begin{array}{|ll|}.210 & .000 \\
\end{array}$ & .189 .001 & \begin{tabular}{|ll}
.000 \\
\end{tabular} & .088 .133 & $\begin{array}{|ll|}.118 & .045 \\
\end{array}$ & $.114 \quad .000$ & \begin{tabular}{|ll}
288.000 \\
\end{tabular} & 252.000 \\
\hline $\mathrm{De}$ & $\begin{array}{|ll|}.239 & .000 \\
\end{array}$ & .204 .000 & .391 .000 & .045 .444 & $.161 \quad .006$ & $\begin{array}{|ll|}.061 & .061 \\
\end{array}$ & 334.000 & 289.000 \\
\hline Del & $\begin{array}{|ll|}185 & .002 \\
\end{array}$ & .209 .000 & $.351 \quad .000$ & .258 .000 & $.320 \quad .000$ & $.320 \quad .000$ & 294.000 & $349 \quad .000$ \\
\hline egration & $\begin{array}{|ll|}.245 & .000 \\
\end{array}$ & .210 .000 & .354 .000 & .160 .006 & $\begin{array}{|ll|}.001 & .001 \\
\end{array}$ & $\begin{array}{|ll|}.001 & .001 \\
\end{array}$ & 334.000 & $\begin{array}{ll}317 & .000 \\
\end{array}$ \\
\hline
\end{tabular}

\section{REFERENCES}

[1] FOULDS, G. A. , CAINE, T.M., CREASY, M.A. (1960). Aspects of Extra- and Intropunitive expression in Mental Illness. J. Ment. Sci. 106:599-610

[2] FOULDS GA. (1965). Personality and Personal Illness. Tavistock. London.

[3] CAINE, T.M. (1960). The expression of Hostility and Guilt, in Melancholic and Paranoid Women. J. Cons. Psychol. 24:18-22

[4] MAYO, P.R. (1969). Women with Neurotic symptoms who do not seek treatment. Br. J. Med. Psychol. 42:165-169.

[5] CAINE TM, FOULDS GA, HOPE K. (1967). Manual of the Hostility and Direction of Hostility Questionnaire. London, University of London Press.

[6] McPHERSON FM. (1988). A note on the female norms of the HDHQ. Brit. J Clin. Psychol. 27: 263-264

[7] ECONOMOU M, ANGELOPOULOS NV. (1989): Dysthymic Symptoms, Hostility and Scholastic Achievement in a Group of High School Students. Educ. Psychol. 9(4): 331-337.

[8] LYKETSOS GS, BLACKBURN IM, TSIANTIS J. (1978). The movement of hostility during recovery from depression. Psychological medicine 8: 145-149.

[9] ANGELOPOULOS N.V., TZIVARIDOU D., NIKOLAOU N., PAVLIDIS N. (1995). Psychiatric Symptoms, hostility features and stressful life events in patients with cancer. Acta Psychiatrica Scandinavica 92: 44-50.

[10] ANGELOPOULOS, N.V., MANTAS, C., MASSALAS, K., VASALOS, K., TSIANOS, E. (1996). Psychiatric symptoms hostility and life events in ulcerative colitis patients during active phase and remission. Europ. J. Psychiat. 10(2):87-99

[11] FOULDS, G.A., BEDFORD, A. (1975). Hierarchy of Classes of personal illness. Psychol. Med. 5: 181-192.

[12] FOULDS GA., BEDFORD, A. (1977). Hierarchies of Personality Deviance and Personal illness. Brit. J. Med. Psychol. 50:73-78.

[13] NORUSIS M. (1993). SPSS for Windows: Base System User's Guide: Release 6.0. SPSS Inc. Chicago, Ill.

[14] KENDALL MG. Rank Correlation Methods. Griffin, London, 1962

[15] PRIEST RG. The homeless person and the psychiatric services: An Edinburgh survey. Brit. J. Psychiatry. 1976: 128: 128-136.

[16] JUNG, C. (1917). Collected papers on Analytical Psychology. London: Baillere, Tindal and Cox. $2^{\text {nd }}$ ed.

[17] BEDFORD, A., FOULDS, G.A. (1977). Validation of the Delusions-Symptoms-States Inventory. Brit. J. med. Psychol. 50, 163-171.

[18] PRIEST RG. (1969). The function of thought disorder: A postulate. Brit. J. Psychiatry 115:959-960. 